\title{
Colonic perforation during percutaneous nephrolithotomy: An 18-year experience
}

\author{
Mohammad AsIZare, MD; Mohammad Reza Darabi, MD; Behnam Shakiba, MD; Leila Gholami-Mahtaj, MSc
}

Mashhad University of Medical Sciences, Mashhad, Islamic Republic of Iran

Cite as: Can Urol Assoc J 2014;8(5-6):e323-6. http://dx.doi.org/10.5489/cuaj.1646

Published online May 21, 2014.

\section{Abstract}

Introduction: Percutaneous nephrolithotomy $(\mathrm{PCNL})$ is the treatment of choice for large, extracorporeal lithotripsy failure stones and those in the inferior calyx. Despite the development of new techniques and the increasing experience in recent decades, complications may still occur. Colonic perforation is one of the most dangerous and rare complications of $\mathrm{PCNL}$, which may lead to peritonitis and sepsis. We present our 18-year experience on the diagnosis and management of colonic perforation during PCNL.

Methods: We retrospectively reviewed the data of $5260 \mathrm{PCNL}$ procedures performed between May1995 and August 2013. Preoperative and operative factors, such as age, sex, history of previous ipsilateral stone intervention, stone side, stone location, site of skin puncture and punctured calyx, were reviewed in patients with colonic injury.

Results: Colonic perforation was found in 11 patients $(5$ males and 6 females) and the mean age was $40.4 \pm 22.2$ years (range: 4 to 71). All injuries were retroperitoneal. The left side was affected in 5 patients and the right side was injured in 6 cases. Conservative management was the treatment planned for all patients. It included withdrawal of the nephrostomy tube outside the kidney to the colon as a percutaneous colostomy, insertion of a double-J ureteral stent, intravenous broad-spectrum antibiotics, bowel rest and total parenteral nutrition. Under this conservative management, complete healing of the colon was achieved in all patients.

Conclusion: Early diagnosis and conservative management of colonic perforation can minimize patient morbidity and mortality and result in excellent healing of the fistulous tract without any serious complications.

\section{Introduction}

Percutaneous nephrolithotomy $(P C N L)$ as a treatment for renal stones was initially described by Fernstrom and Johansson in 1976. ${ }^{1}$ Today, this procedure is the treatment of choice for large, hard, infected, extracorporeal lithotripsy failure stones and those in the inferior calyx. ${ }^{2,3}$ Despite the development of new techniques, improvement of technology and increasing experience in the recent decades, complications still occur. Colonic perforation is one of the most dangerous and rare complications of PCNL, occurring in about $0.3 \%$ of procedures. ${ }^{4}$ Untreated colonic perforation may lead to renal abscess, nephrocolic or colocutaneous fistula, peritonitis and sepsis. ${ }^{4,5}$ However, there are few reports on the risk factors and management of colonic injury during PCNL. We present our 18-year experience on the management of colonic perforation during percutaneous renal operations.

\section{Methods}

We retrospectively reviewed the data of $5260 \mathrm{PCNL}$ procedures performed between May1995 and August 2013. All surgeries were performed in 3 main hospitals of Mashhad, Iran, by 2 surgeons. After routine preoperative evaluation, patients underwent general anesthesia. Cystoscopy was performed and a 5-Fr open-ended ureteral catheter was inserted into the lithotomy position. Patients were then placed in the prone position with pressure sites and chest support. PCNL was performed in the routine manner. Percutaneous access was created by fluoroscopy guidance as the standard approach. The nephrostomy tract was dilated using Alken dilators or the one-shot technique and a 30-Fr or 28-Fr Amplatz sheath was positioned in the renal collecting system. The nephroscopy was done with a rigid nephroscope. Small stones were removed with irrigation and/or grasping forceps and large ones were fragmented with pneumatic devices. A 22-Fr nephrostomy tube was fixed at the end of the procedure for 48 hours. The ureteral catheter and a 16-Fr Foley urethral catheter were removed 72 hours after surgery. On the first postoperative day, kidneys, ureters, and bladder (KUB) x-ray were routinely performed in all patients for evaluation of possible stone remnants.

Preoperative and operative factors, such as age, sex, history of previous ipsilateral stone intervention, stone side, stone location, site of skin puncture and punctured calyx, 
were retrospectively reviewed in patients with colonic injury. The study protocol was approved by the Vice-Chancellor of Research Ethics Committee of Mashhad University of Medical Sciences, Islamic Republic of Iran.

\section{Results}

Out of the $5260 \mathrm{PNL}$ procedures, colonic perforation occurred in 11 patients $(0.2 \%)$. They consisted of 5 males and 6 females, with a mean age of $40.4 \pm 22.2$ years (range: 4 to 71 ). Five patients had a history of ipsilateral open pyelolitotomy. One case had undergone previous laparatomy for intestinal perforation due to a gunshot injury 15 years before the PCNL procedure. Staghorn, multiple renal stones and single stones were seen in 4, 4 and 3 patients, respectively. The right colon was injured in 6 patients. All cases had lower caliceal punctures. Colonic injury was diagnosed in 3 cases intraoperatively (Fig. 1). In 8 patients, colonic injury was diagnosed during the postoperative period; after removal of the nephrostomy tube, passage of gas and some fecaloid material was observed in these 8 cases. In an 11-year-old girl, when the nephrostomy tube was removed, fecaloid material and a number of Enterobius vermicularis were drained. In another case colonic perforation occurred during left PCNL in a horseshoe kidney; the remaining cases

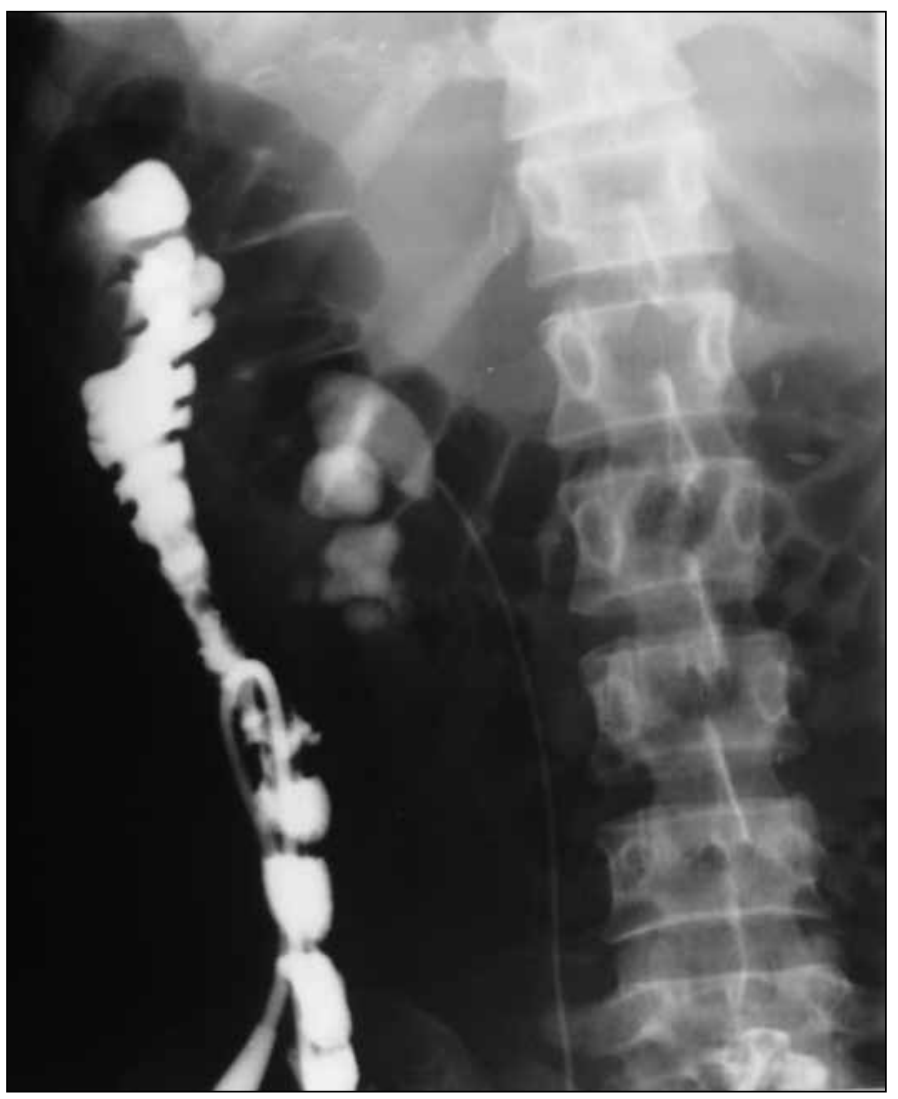

Fig. 1. Nephrostography showing opacification of ascending colon. had a normal kidney in size and location.

Fever was detected in all patients, but acute abdomen was not seen in any case. Conservative management was planned for all patients and no emergent operative intervention was needed because all perforations were retroperitoneal. The conservative management included withdrawal of the nephrostomy tube outside the kidney to the colon as a percutaneous colostomy, insertion of a double-J ureteral stent, intravenous broad-spectrum antibiotics, bowel rest and total parenteral nutrition. The tube was removed between days 10 and 14 . One month after termination of fecaloid leakage, the double J stent was removed and all patients underwent intravenous pyelogram to confirm a curative response. Under this conservative management, complete healing of the colon was seen between days 10 to 16 in all patients, except 1 . In this single patient, the colocutaneous fistula was not healed after 2 weeks despite conservative management. He was a 42-year-old with a history of laparotomy for intestinal perforation due to bullet injury in the Iran-Iraq war. It was decided to perform colostomy and surgical management, but the patient refused this treatment plan. After 23 days, he was successfully treated with conservative management.

\section{Discussion}

PCNL is a safe and effective technique to treat renal stones, especially large or multiple renal calculi. Despite the invasiveness of PCNL, its complication rates are low (3\%-4\%), ${ }^{4,6}$ latrogenic colonic perforation is a serious but rare complication of PCNL. There are few reports on the prevalence and management of this rare complication. Kachrilas and colleagues studied 1026 patients undergoing PCNL and 5 patients reported colonic perforation. ${ }^{7}$ Mousavi-Bahar and colleagues analyzed the medical records of 671 PCNL procedures in a single urologic centre and found colonic perforation in 2 patients $(0.3 \%){ }^{2}$ A large retrospective study on this rare complication was done by El Nahas and colleagues. ${ }^{4}$ The authors reviewed 5039 patients who underwent the PCNL procedure, and the reported incidence of colonic perforation was $0.3 \%$. Our present study showed the incidence of colonic perforation to be about $0.2 \%$, lower than previous studies. Due to the low rate of colonic perforation, we did not change our approach and did not assess colonic injury at the end of the surgery routinely. However, in patients with a history of surgery in the ipsilateral kidney, in which the risk of perforation is higher, a computed tomography $(\mathrm{CT})$ scan was used to assess the anatomic correlation between the colon and the kidney.

Previous studies have reported some risk factors for colonic perforation, including advanced patient age, a markedly dilated pelvic-calyceal system, megacolon, and horseshoe kidney. ${ }^{7-10}$ In most studies, the most frequent etiology for 


\begin{tabular}{lccccccc}
\hline \multicolumn{2}{l}{ Table 1. Patient characteristics } & & & & \\
\hline Number & Sex & $\begin{array}{c}\text { Age } \\
\text { (years) }\end{array}$ & Side & $\begin{array}{c}\text { Previous ipsilateral } \\
\text { stone intervention }\end{array}$ & Stone number & Site of skin puncture & Punctured calyx \\
\hline 1 & Male & 65 & Left & open surgery & Single & Subcostal & Lower \\
2 & Male & 42 & Right & No & Single & Subcostal & Lower \\
3 & Male & 32 & Right & No & Staghorn & Subcostal & Lower \\
4 & Female & 11 & Left & No & Multiple & Subcostal & Lower \\
5 & Female & 4 & Right & No & Multiple & Subcostal & Lower \\
6 & Female & 71 & Right & No & Multiple & Subcostal & Lower \\
7 & Male & 68 & Left & Open surgery & Staghorn & Subcostal & Lower \\
8 & Female & 43 & Right & Open surgery & Staghorn & Subcostal & Lower \\
9 & Female & 51 & Left & Open surgery & Multiple & Subcostal & Lower \\
10 & Male & 26 & Right & No & Staghorn & Subcostal & Lower \\
11 & Female & 33 & Left & Open surgery & Single & Subcostal & Lower
\end{tabular}

colon perforation during PCNL is the retrorenal or posterolateral position of the colon. ${ }^{4}$ Based on the abdominal CT scan, a posterorenal colon is usually found in $0.9 \%$ to $16.1 \%$ of the general population. This normal variation is higher in the prone compared to the supine position and in the left rather than the right side. ${ }^{11-13}$ These findings may explain the greater risk of colonic perforation in the left side and prone position, which has been reported in previous studies. ${ }^{4,14}$ To prevent colon perforation during PCNL, some experts have recommended that preoperative CT scan may be useful. CT or fluoroscopic-guided puncture of the pelvicaliceal system can reduce the risk of colon puncture by better visualization of the gas containing colon behind the kidney. ${ }^{15,16}$ In our study, colonic perforation occurred in the 5 descending colon after left-sided PCNL, but the difference between the prevalence of left- and right-side injury was not significant. This discrepancy between the present study and previous reports may be described in 2 ways: First, 6 patients in the present study had undergone either a previous kidney surgery or laparotomy. These manipulations result in some changes in the position of organs in relation to each other. Secondly, this could be associated with other risk factors which the present and previous studies have not yet assessed.

The diagnosis was based on symptoms and signs that occurred immediately or several days after PCNL. An abdominal CT scan or opacity visualization in the colon during antegrade or retrograde pyelography provides a simple way to confirm the diagnosis.

The first step in the treatment of colon perforation should be based on conservative management. This includes separating the nephrocolic communication, including double J stent insertion for adequate urinary drainage and retraction of the nephrostomy tube from the pelvicalicial system into the colon as a percutaneous colostomy tube. Other conservative strategies include broad spectrum antibiotics covering gram negative and anaerobic bacteria and parenteral nutri- tion. Occasionally, surgery is indicated in intraperitoneal perforation, peritonitis, sepsis and persistent nephrocutaneous fistula. ${ }^{7,17}$ In the recent years, some researchers have shown optimal primary results of fibrin glue application to correct persistent nephrocutaneous fistulas in some cases. ${ }^{18}$

\section{Conclusion}

Colonic perforation is a rare complication of $\mathrm{PCNL}$, for which early diagnosis and conservative management can minimize patient morbidity and mortality. Conservative management can lead to excellent healing of the colonic perforation.

Competing interests: Dr. Darabi, Dr. AslZare, Dr. Shakiba and Dr. Mahtaj all declare no competing financial or personal interests.

This paper has been peer-reviewed.

\section{References}

1. Fernstrom I, Johannson B. Percutaneous pyelolithotomy: A new extraction technique. Scand J Urol Nephrol 1976;10:257.

2. Mousavi-Bahar SH, Mehrabi S, Moslemi MK. Percutaneous nephrolithotomy complications in 671 consecutive patients: A single-center experience. Urol J 2011;8:271-6.

3. Skolarikos A, Alivizatos G, De La Rosette JJMCH. Percutaneous nephrolithotomy and its legacy. Eur Urol 2005;47:22-8. http://dx.doi.org/10.1016/j.eururo.2004.08.009

4. El-Nahas AR, Shokeir AA, E-Assmy AM, et al. Colonic perforation during percutaneous nephrolithotomy: Study of risk factors. Urology 2006;67:937-41. http://dx.doi.org/10.1016/i.urology.2005.11.025

5. Wolf JS Jr. Management of intraoperative diagnosed colonic injury during percutaneous nephrolithotomy. Tech Urol 1988;4:160-4

6. el-Kenawy MR, el-Kappany HA, el-Diasty TA, et al. Percutaneous nephrolithotomy for renal stones in over 1000 patients. Br J Urol 1992;69:470-5. http://dx.doi.org/10.1111/j.1464-410X.1992.tb15590.x

7. Kachrilas S, Papatsoris $A$, Bach C, et al. Colon perforation during percutaneous renal surgery: A 10-year experience in a single endourology centre. Urol Res 2012;40:263-8. http://dx.doi.org/10.1007/ s00240-012-0475-1

8. Vallancien $G$, Capdeville R, Veillon B, et al. Colonic perforation during percutaneous nephrolithotomy. J Urol 1985;134:1185-7. 
Darabi et al.

9. Noor Buchholz NP. Colon perforation after percutaneous nephrolithotomy revisited. Urol Int 2004;72:8890. http://dx.doi.org/10.1159/000075282

10. Rodrigues Netto N, Lemos GC, Fiuza IL. Colon perforation following percutaneous nephrolithotomy. Urology 1998;32:223-4. http://dx.doi.org/10.1016/0090-4295(88)90388-3

11. Hopper KD, Sherman JL, Luethke JM, et al. The retrorenal colon in the supine and prone patient. Radiology 1987;162:443-6.

12. Prassopoulos $\mathrm{P}$, Gourtsoyiannis $\mathrm{N}$, Cavouras $\mathrm{D}$, et al. A study of the variation of colonic positioning in the pararenal space as shown by computed tomography. Eur J Radiol 1990;10:44-7. http://dx.doi. org/10.1016/0720-048X(90)90086-0

13. Boon JM, Shinners B, Meiring JH. Variations of the position of the colon as applied to percutaneous nephrostomy. Surg Radiol Anat 2001;23:421-5. http://dx.doi.org/10.1007/s00276-001-0421-3

14. Chalise PR, Sharma UK, Gyawali PR, et al. Renocolic fistula following percutaneous nephrostomy: A case report. Nepal Med Coll J 2009;1 1:143-4.

15. Skolarikos A, de la Rosette J. Prevention and treatment of complications following percutaneous nephrolithotomy. Curr Opin Urol 2008;18:229-34. http://dx.doi.org/10.1097/MOU.0b013e3282f46afc
16. Rodrigues Netto $\mathrm{N} \mathrm{Jr}$, Lemos GC, Fiuza JL. Colon perforation following percutaneous nephrolithotomy. Urology 1988;32:223-4. http://dx.doi.org/10.1016/0090-4295(88)90388-3

17. Traxer 0 . Management of injury to the bowel during percutaneous stone removal. J Endourol 2009;23:1777-80. http://dx.doi.org/10.1089/end.2009.1553

18. Miranda EP, Ribeiro GP, Almeida DC, et al. Percutaneous injection of fibrin glue resolves persistent nephrocutaneous fistula complicating colonic perforation after percutaneous nephrolithotripsy. Clinics (Sao Paulo) 2009;64:711-3. http://dx.doi.org/10.1590/S1807-59322009000700017

Correspondence: Dr. Mohammad Reza Darabi, Mashhad University of Medical Sciences, Mashhad, Islamic Republic of Iran; darabimmr@mums.ac.ir 